\title{
Analysis of synthetic humic substances for medical and environmental applications by capillary zone electrophoresis
}

\author{
Ph. Schmitt-Kopplin ${ }^{1}$, D. Freitag ${ }^{1}$, A. Kettrup ${ }^{1}$, N. Hertkorn ${ }^{1}$, U. Schoen², R. Klöcking ${ }^{3}$, B. Helbig ${ }^{3}$, \\ F. Andreux ${ }^{4}$ and A.W. Garrison ${ }^{5}$ \\ ${ }^{1}$ GSF, Forschungszentrum für Umwelt und Gesundheit, Institut für Ökologische Chemie, D-85764 Neuherberg, Germany \\ ${ }^{2}$ Katholische Universität Eichstätt, Phys. Geogr., FR Landschaftsökologie, D-85072 Eichstätt, Germany \\ ${ }^{3}$ Friedrich-Schiller-Universität Jena, Institut für Antivirale Chemotherapie, D-99089 Erfurt, Germany \\ ${ }^{4}$ Equipe Géosol, Centre des Sciences de la Terre, Université de Bourgogne, F-21000 Dijon, France \\ ${ }^{5}$ National Exposure Research Laboratory, U.S. Environmental Protection Agency, Athens, Georgia 30605-2720, USA
}

Capillary electrophoretic methods (CZE, CIEF) have been found to be useful tools for the analysis of the electrophoretic behaviour of anionic polyelectrolytes like humic substances. The humic substances give an homogeneous signal in CZE with a Gaussian distribution of the detection signals around an average electrophoretic mobility (AEM) corresponding to the charge density distribution of the humic substances governed by their molecular size and their acidities. Natural humic substances as well as phenolic polymerisates are only present as anions and the presented electrophoretic methods can be used as a tool for the rapid evaluation of their relative charge densities, an important parameter when studying their reactivity towards organic and metallic species.

\section{Introduction}

Natural organic matter contributes significantly to the behaviour of anthropogenic chemicals in surface water, soils and sediments. Humic substances can constitute up to $50 \%$ of natural organic matter and are known to bind chemicals, governing the transport and bioavailability of xenobiotics and thus participating in the flux of pesticides and other contaminants to water reservoirs. Humic substances are also the reactive fraction of peats, well-known for their therapeutic properties already in Babylonian and Roman Empire times. Humic substances have several therapeutically relevant characteristics such as antiviral, antiinflammatory, estrogenic, profibrinolytic and heavy metal-binding activities [1]. Similar activities can be attributed to synthetic humic substances (oxidative polymerisates of $\mathrm{o}-$ and $\mathrm{p}$-diphenols). 
In contrast to natural humic substances, the structure of synthetic polymers may be controlled by selecting the phenolic basic compound thus improving their therapeutic indication. In terms of environmental processes these specific synthetic polymers can be used as structurally different matrices (polydispersities, molecular size distributions, nitrogen contents), for example to study of pollutants binding [2].

The structural chemistry of humic substances is much less known than the chemistry of any biopolymer of animal origin [3]. Humic substances are known to be high molecular mass polyhydroxycarboxylates comprised of polyaromatic and aliphatic subunits. The degree of ionization of these macromolecules is governed by the amount of ionized phenolic and carboxylic groups of the humic core, which is a function of solution $\mathrm{pH}$. Compared to the operationally defined fulvic acids (soluble in both alkali and acid solutions), the humic acids (soluble in alkali, insoluble in acid solutions) are of higher molecular mass and lower acidity.

Humic molecules have an anionic character and migrate in a capillary electrophoresis system if the separation buffer has a $\mathrm{pH}$ value above 3.5. Regardless of the apparent match between humic substances analytes and capillary electrophoresis technology, only few researchers have tried to apply any techniques of capillary electrophoresis to the study of humic substances [4-10], coal extracts [11] or lignin related compounds $[12,13]$. Capillary electrophoresis techniques for the study of the interaction of humic substances with pollutants are only in their infancy [14-18]. In addition, our first work in this area [7] indicated that borate buffers interact with humic acids, drastically changing the electropherograms while only slightly altering the $\mathrm{pH}$. We then showed with complemental ${ }^{11} \mathrm{~B}-\mathrm{NMR}$ spectroscopy experiments that these changes were caused by the complexation of borate ions with cis-diol groups within the humic acid mixtures [19].

This paper is intended to illustrate the present knowledge and limitations of capillary electrophoresis in the characterization of humic substances and to give an example of the use of capillary electrophoresis in the rapid analysis of different synthetic humic mixtures.

\section{Material and Methods}

\section{Instrumentation}

Instrumentation consisted of a BioFocus ${ }^{\mathrm{TM}} 3000$ Capillary Electrophoresis System from Biorad Laboratories and a Beckman P/ACE 2100 Series capillary electrophoresis system with the Beckman System Gold Chromatography Software.

\section{Capillary Zone Electrophoresis (CZE)}

Uncoated fused-silica capillary electrophoresis columns (75 $\mu \mathrm{m} \mathrm{id}, 375 \mu \mathrm{m} \mathrm{od}, 50 \mathrm{~cm}$ length to the detector, total length $57 \mathrm{~cm}$ ) were obtained from Biorad Laboratories and Beckman Instruments, Inc. Typical zone electrophoresis conditions for separation of the various humic substances fractions were: separation buffer, $50 \mathrm{mM}$ acetate $(\mathrm{pH} 4.95)$,

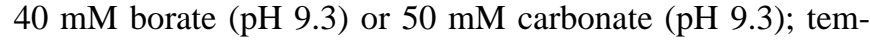
perature, $30{ }^{\circ} \mathrm{C}$; voltage, $20 \mathrm{kV}$; detector wavelength, 254 $\mathrm{nm}$ or scanning from $200 \mathrm{~nm}$ to $360 \mathrm{~nm}$ (2 nm step); hydrodynamic injection, 5 or $10 \mathrm{~s}$. Capillary zone electrophoresis gave good reproducibility of migration times - a standard deviation of $0.06 \min (0.89 \% ; n=5)$ with Scheyern soil humic acids (described in [16]). The sample concentration in humic substances had no significant influence on the average electrophoretic mobility (AEM). Day to day changes in migration times occurring because of relative changes in the electroosmotic flow (different capillary surface conditions) could be controlled by washing the capillary with $0.1 \mathrm{M}$ $\mathrm{NaOH}$ for 2 min between each run.

\section{Humic substances (HS)}

Soil humic (HA) and fulvic acids (FA) were extracted and isolated according to procedures of the International Humic Substances Society (IHSS); standard soil and water humic substances were obtained from the IHSS, Dr. P.R. Bloom, Departement of Soil, Water and Climate, University of Minnesota, St. Paul, MN 55108 USA. The synthetic humic substances were those prepared and described in [1] for medical applications and in $[2,20]$ to modelise metal and pesticides adsorptions to defined organic matrices. The polymer catechol 1 (HS 1500) is a synthetic polymer for medical use kindly obtained from B. Seubert, Rütgerswerke AG, Fankfurt am Main, Germany (Europeen patent office, EP0537430A1, 01.08.1992).

For capillary electrophoresis analysis, the humic fractions were dissolved in $0.1 \mathrm{M} \mathrm{NaOH}$ to a concentration of about $1 \mathrm{mg} / \mathrm{mL}$. The lowest measurable concentration (without stacking conditions) was $50 \mu \mathrm{g} / \mathrm{mL}$.

\section{The capillary zone electrophoresis separation technique}

After filling the capillary with the separation buffer, the quartz capillary wall is negatively charged (ionization of the silanol groups; the pI of fused silica is about 1.5) and attracts positively-charged ions from the buffer, creating an electrical double layer. With application of the voltage across the capillary, the cations of the double layer migrate to the cathode creating a net flow of buffer solution to the negative electrode (electroosmotic flow - EOF). The retention time does not reflect the effective electrophoretic mobilities $\mu$ of the analytes in the separation system which is independent of the electroosmotic flow. The effective electrophoretic mobilities $(\mu)$ of the analytes are calculated by subtracting the electroosmotic flow $\left(\mu_{\text {eof }}\right)$ from the measured electrophoretic mobilities $\left(\mu_{\text {mes }}\right)$. 
The effective mobility $(\mu)$ is a fundamental parameter that can be approximated by the Debye-Huckel-Henry theory when using small molecules, as follows:

$$
\mu=\frac{q}{6 \cdot p \cdot \eta \cdot R}
$$

(where $q$ is the net charge and $R$ the Stokes radius of the analyte, $\eta$ the viscosity of the separation buffer).

Semi-empirical models, already described in the sixties [21] to predict mobilities of peptides in electrophoretic separation systems, were adapted to capillary electrophoresis separation of polypeptides and proteins: $\mu$ can be described with a charge-to-size model where the size of the molecules is approximated by their molecular mass $\mathrm{M}$. It was found to be a continuous function of $\mathrm{M}^{-1 / 3}$ to $\mathrm{M}^{-2 / 3}$, depending on the magnitude of $\mathrm{M}$ and the ionic strength of the buffer [22]. Because a good correlation can be found between the mobilities and the charge densities of the studied analytes, both charge per molar volumes and charge per molar surfaces of the analyte can also be involved in a similar formula. The theoretical charge $Z$ of small molecules can be calculated at each $\mathrm{pH}$, knowing the dissociation constants $\left(\mathrm{pK}_{\mathrm{a}}\right)$. Thus the knowledge of the structure of the analytes allows a good prediction of the electrophoretic mobilities and the separation potential in capillary zone electrophoresis. Simillar prediction models are currently developed for the separation in $\mathrm{pH}$ gradients with capillary isoelectric focusing (CIEF) [23].
Many capillary electrophoresis methods were developed for the separation of small molecules (pesticides, bactericides, aliphatic and phenolic acids, sugar acids [24-26]) and for the determination of their physico-chemical parameters from their electrophoretic behaviour (dissociation constants $\mathrm{pK}_{\mathrm{a}}$, isoelectric points pI, hydrophobicities $\log P$ ) [25].

The electrophoretic behaviour of macromolecular polyhydroxycarboxylates like humic acids can be better described when the electrophoretic behaviour of smaller structural model molecules is well understood. Theoretical models for the charge density prediction of aliphatic or phenolic anions are in good accordance with their measured mobilities at different separation $\mathrm{pH}$. Figure 1 gives an example of the evolution of the theoretical charge densities for different lignin monomers with increasing $\mathrm{pH}$.

From figure 1 one can see that by chosing the separation $\mathrm{pH}$ (around $\mathrm{pH} 5, \mathrm{pH} 9$ or over $\mathrm{pH} 11$ ), different phenolic classes can be distinguished according to their number of carboxylic and/or hydroxylic substituants. The real mobilities of a mixture of 30 phenolic compounds and of a catechol polymer at $\mathrm{pH} 5.1, \mathrm{pH} 9.1, \mathrm{pH} 11.1$ is illustrated in figure 2 . With these phenols, different mobility areas corresponding to specific charge density distributions can be defined, allowing strong constraints on the structure of the catechol polymer (net charge distribution at the given $\mathrm{pH}$ and the size/shape distribution of the humic molecules).

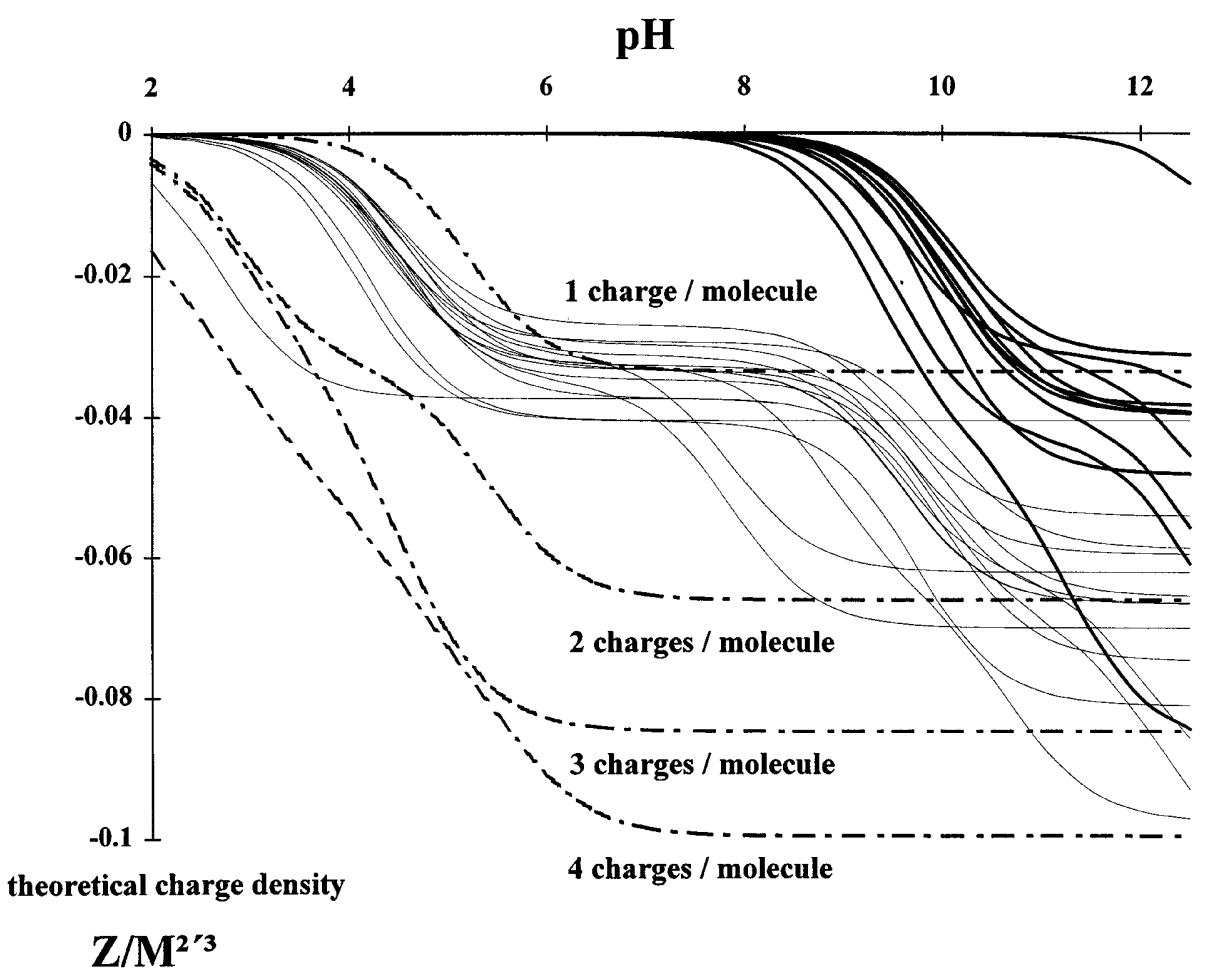

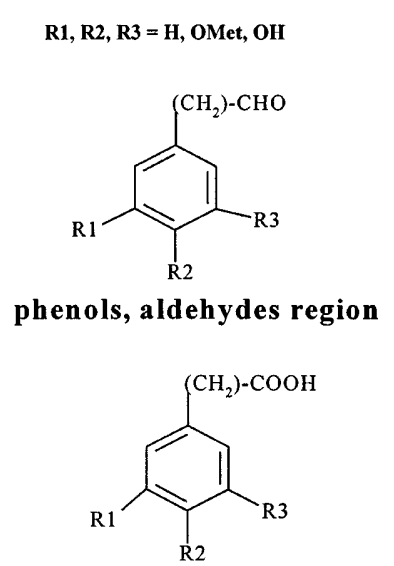

phenolic acids region<smiles>O=C(O)c1ccc(C(=O)O)cc1</smiles>

carboxylic acid region

Figure 1. Theoretical changes in charge densities (expressed as $Z / M^{23}$ ) of different substituted phenols as a function of $\mathrm{pH}$. 
30 phenols mixture
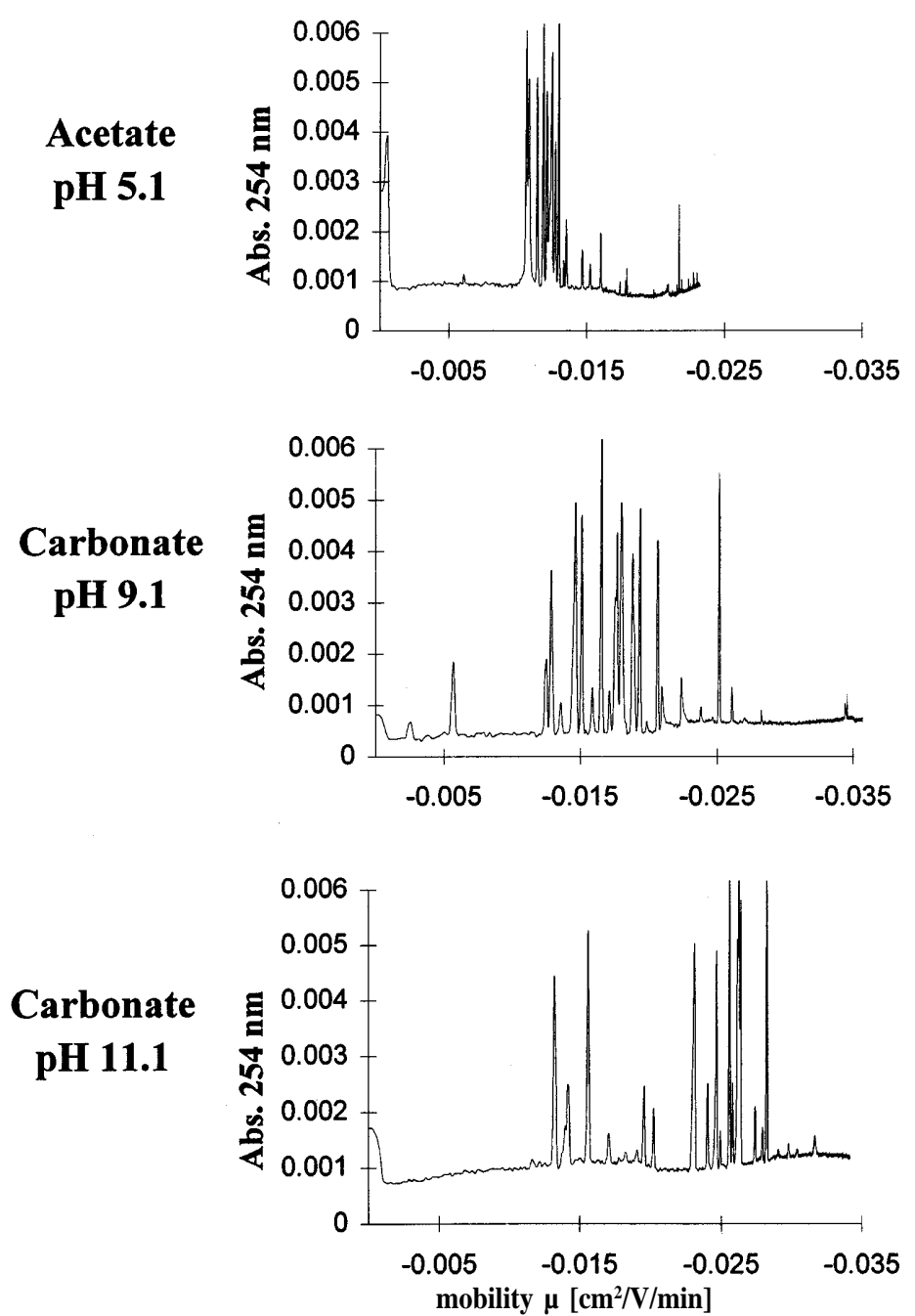

catechol polymer
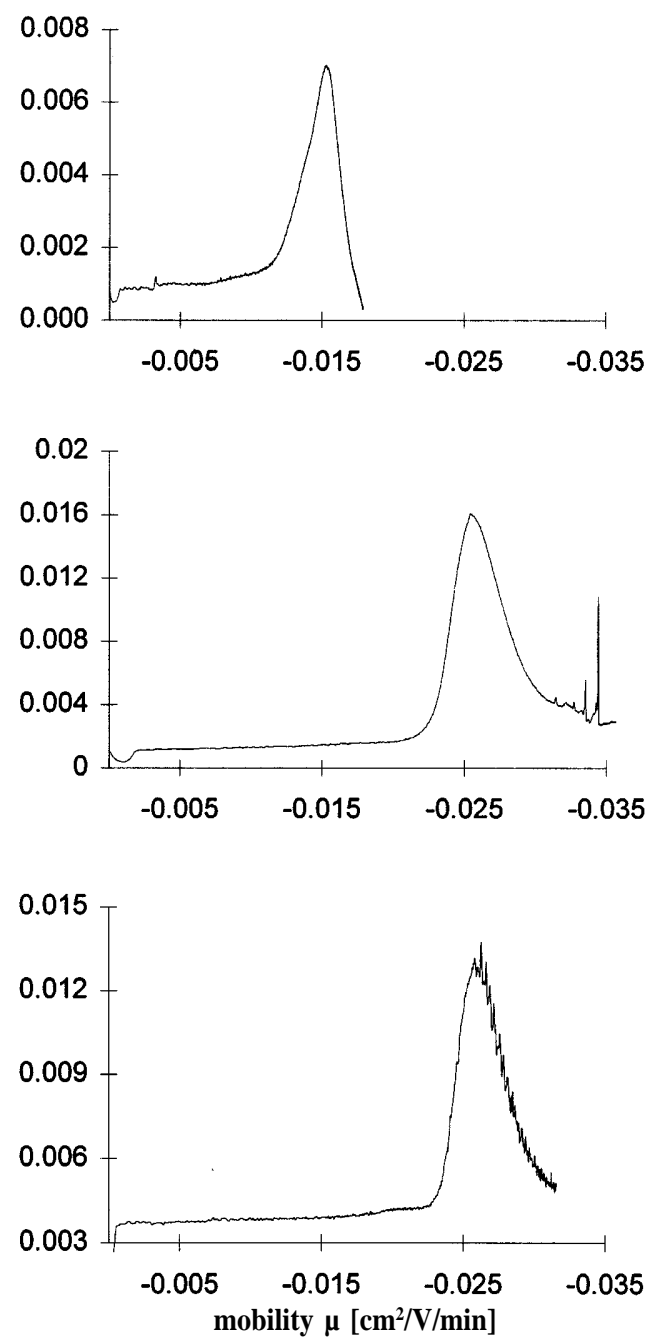

Figure 2. Real mobility distribution of a mixture of 30 phenolic compounds and of a catechol polymer at $\mathrm{pH} 5.1, \mathrm{pH} 9.1$ and pH 11.1.

In this case capillary electrophoresis has been used as a fingerprint method but can also contribute to the determination of the charge density distribution in the polymer-mixture at different $\mathrm{pH}$.

\section{Influence of the separation buffer in CZE}

Special attention must be given to the interpretation of capillary electrophoresis electropherograms because they can be significantly influenced by the type of the separation buffer system. In previous studies the authors showed that soil fulvic acids exhibit a consistent and characteristic set of sharp peaks (mainly phenolic acids), extending from a humic "hump"; the corresponding humic acids only gave the "hump", which sometimes presents shoulders but little definition [7]. Depending on the molarity of borate ions in the separation buffer remarkable peak-sharpening can be observed caused by the interaction of borate ions with 1,2and 1,3-diols present in the humic mixtures (Fig. 3a); humic acids exhibit electropherograms with sharp peaks extending from the "humic hump" and corresponding to borate complexes [27]. The variations of migration times of these peaks depend on the concentration of borate ions from the separation buffer. The complexation of borate ions and humic acids fractions was also analysed with ${ }^{11} \mathrm{~B}$ - and ${ }^{1} \mathrm{H}-\mathrm{NMR}$ spectroscopy as well as UV-spectrophotometry in solutions of the 
same composition as the capillary electrophoresis separation buffers (Fig. 3b). Supplementary studies with model compounds (flavonoids, phenolic and sugar acids) indicated feasible reaction mechanisms leading to a model including the formation of bidentate esters (monocomplexes) as well as spiranes (tetradentate esters or dicomplexes) within humic substructures.

These investigations are the basis for the development of capillary electrophoresis methods parallel to homo- and heteronuclear-NMR-spectroscopy to analyse the interactions between metals and humic susbtances.

\section{Application to selected synthetic humic polymers}

Several synthetic humic polymers were analysed with capillary zone electrophoresis considering the three buffer systems at $\mathrm{pH} 5, \mathrm{pH} 9$ and $\mathrm{pH} 11$ to compare the charge densities induced by carboxylic or phenolic acidities and the $40 \mathrm{mM}$ borate buffer at $\mathrm{pH} 9$ to compare their content of 1,2- and 1,3-diols through their relative borate complexation. These buffers were shown to be good background electrolytes for the rapid comparison of natural humic substances extracted with the IHSS method and reverse osmosis [27]. The corresponding electropherograms with the 4 background electrolytes are given in figure 4. Different observations can be derived from these spectra:

- the polymers obtained from chlorogenic acid, gallic acid, gentisinic acid and caffeic acid (defined in [1]) all present sharp peaks at $\mathrm{pH} 9$ in the high charge density region; in these polymers the fulvic and humic acids were not separated and the sharp peaks derive from low molecular acidic fractions still present in the mixture.

- The polymers obtained from caffeic and chlorogenic acid (catechol type) present a similar borate complexation as compared with the pyrogallol and the hydroquinone type polymers.

- The two different catechol polymers present similar electrophoretic distributions even though being of two different sources.

- The polymers catechol 1, catechol 2, catechol/glycine and catechol/triglycine are humic acid type polymers and do not show the sharp peaks due to oligomeric ionized fractions which are observed in the other polymers at $\mathrm{pH} 9$. However they show such oligomeric ionized structures when $\mathrm{pH}$ in over 11 due to the ionization of the phenolic substructures with $\mathrm{pKa}$ values higher than 10 .

- The addition of glycine and triglycine during catechol oxidation and the integration in the polymer of $\mathrm{COOH}$ charges increase significantly the charge density distributions and polydispersity of the polymers, in the order catechol < catechol/glycine < catechol/triglycin as already observed with other characterization tools [20].

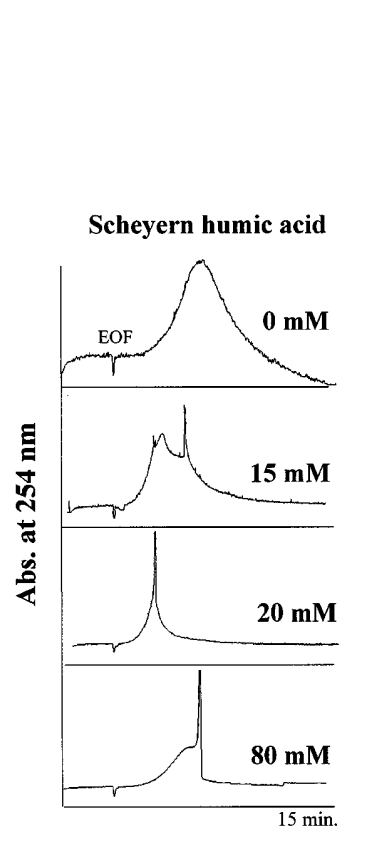

(a)

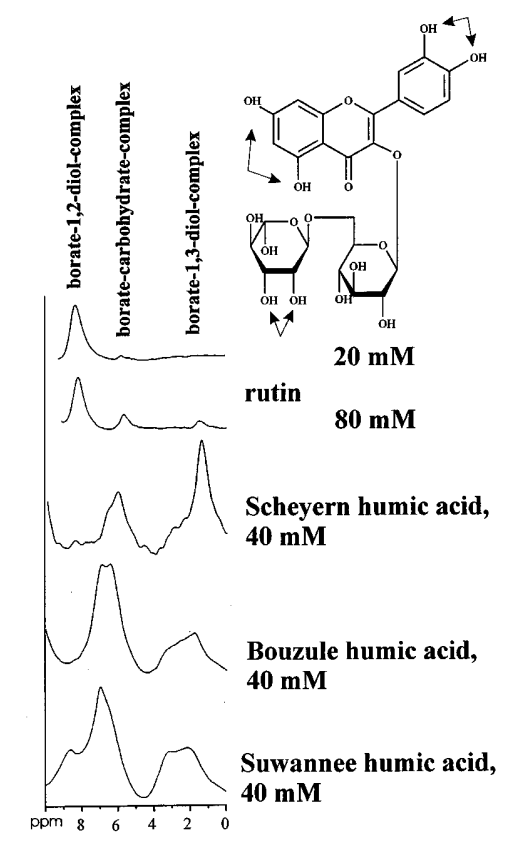

(b)
Figure 3. (a) CZE of a soil humic acid (Scheyern location) at different borate concentrations in the separation buffer (b) ${ }^{11} \mathrm{~B}$ NMR of rutin and different humic acids (HA) at given borate concentrations (the arrows show the borate complexation sites on rutin).

\section{Conclusion}

Capillary zone electrophoresis has been shown to be a rapid method for the analysis of polydisperse polyhydroxycarboxylate. This method not only allows a fingerprinting of humic substances but also the determination of the relative charge densities reflecting the distribution of molecular sizes and charges in the respective polymers. The measurements are carried out in aqueous solutions when both $\mathrm{pH}$ and ionic strength can be controlled; this allows a description of the behaviour of humic substances mixtures in aqueous conditions close to environment and biological media.

\section{Acknowledgements}

Thanks are due to Heidi Neumeir and Eva Schindlbeck, of the Institute for Ecological Chemistry - GSF, for skillful technical assistance. 

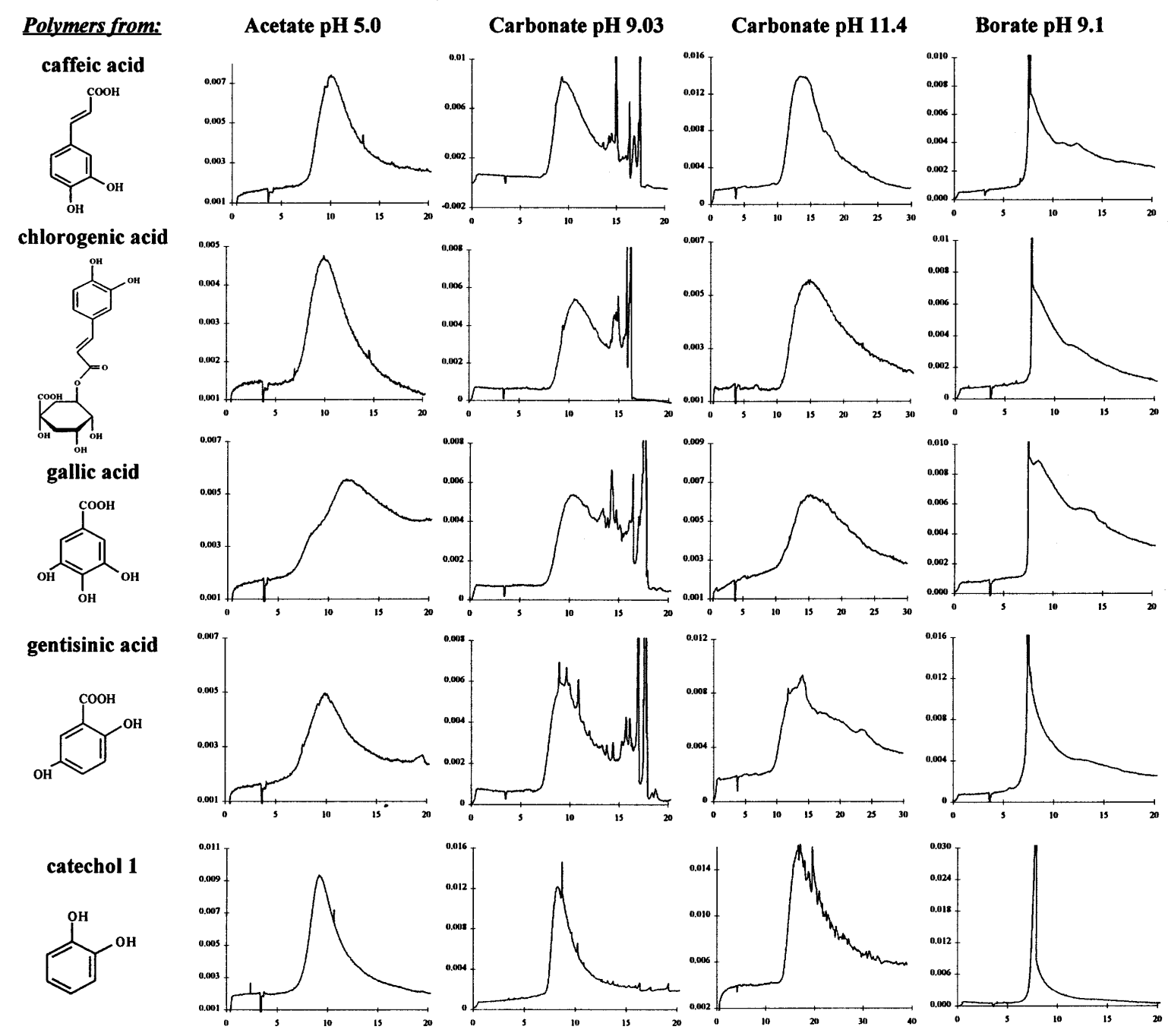

catechol 2
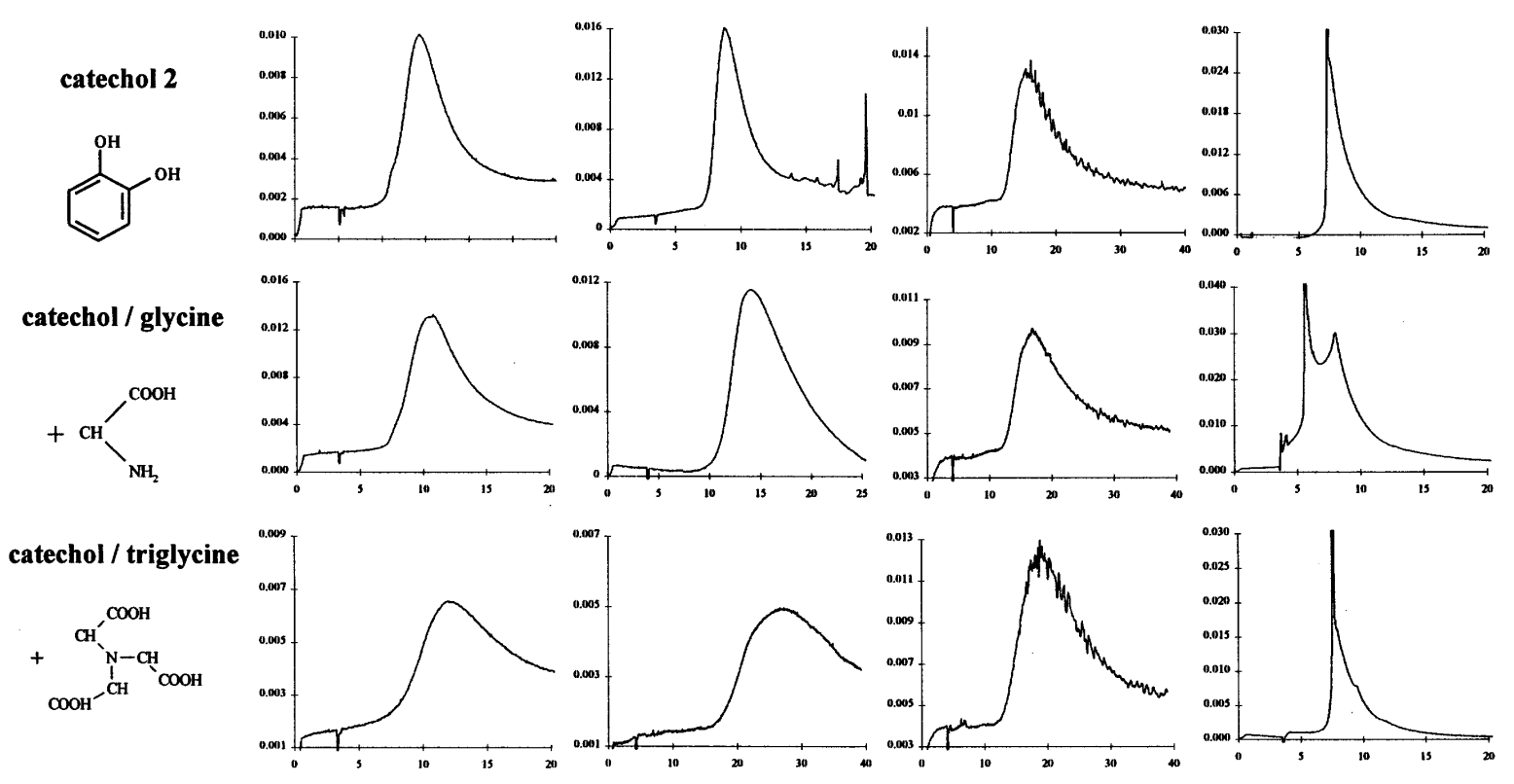

Figure 4. Electropherograms of eight selected synthetic polymers (top to bottom) measured with four different separation buffers (left to right) [y-axis: UV-absorbance at $254 \mathrm{~nm}$; $x$-axis: migration time (min)]. 


\section{References}

1. Klöcking, R. In: Humic Substances in the Global Environment and Implications on Human Health., Senesi, M. and Miano, T.M. Eds, Elsevier Science B.V., 1994, pp 1245-1257.

2. Andreux, F. G.; Portal, J. M.; Schiavon, M.; Bertin, G. The Sci. Tot. Environ. 1992, 117-118, 207-217.

3. Shevchenko, S.; Bailey, G. W. Crit. Rev. Environ. Sci. Technol. 1996, 26, 95-153.

4. Kopacek, K.; Kaniansky, D.; Hejzlar, J. J. Chromatogr. 1991, 54, 5461-470.

5. Schmitt-Kopplin, Ph.; Hertkorn, N.; Schulten, H. R.; Freitag, D.; Kettrup, A. Environ. Sci. Technol. 1998, 32, 2531-2541.

6. Rigol, A.; Lopez-Sanchez, J. F.; Rauret, G. J. Chromatogr. 1994, 664, 301-305.

7. Garrison, A. W.; Schmitt, Ph.; Kettrup, A. Water Res. 1995 , 29, 2149-2159

8. Ciavatta, C.; Govi, M.; Siti, L.; Gessa, C. Commun. Soil Sci. Plant Anal. 1995, 26, 3305-3313.

9. Pompe, S.; Heise, K. H.; Nitsche, H. J. Chromatogr. 1996, 723, 215-218.

10. Wang, X.; Peng, A.; Schmitt, Ph.; Hertkorn; N. Acta Scientiae Circumstantiae 1996, 16, 270-275.

11. Wright. B. W.; Ross, G. A.; Smith, R. D. Energy and Fuel 1989, 3, 428-430.

12. Sjöholm, E.; Nilvebrant, N. O.; Colmsjö, A. J. Wood Chem. Technol. 1993, 13, 529-544.

13. Dahlman, O.; Månsson, K. J. Wood Chem. Technol. 1996, 16, 47-60.
14. Schmitt, Ph.; Trapp, I.; Garrison, A. W.; Freitag, D.; Kettrup, A. Chemosphere 1997, 35, 1997 55-75.

15. Schmitt, Ph.; Freitag, D.; Sanlaville, Y.; Lintelman, J.; Kettrup, A. J. Chromatogr. A 1995, 709, 215-225.

16. Schmitt, Ph.; Garrison, A. W.; Freitag, D.; Kettrup, A. Fresenius J. Anal. Chem. 1996, 354, 915-920.

17. Nordén, M.; Dabek-Zlotorzynska, E. J. Chromatogr. A 1995, 739, 421-429.

18. Nordén, M.; Dabek-Zlotorzynska, E. Electraphoresis 1995, 18, 292-299.

19. Schmitt-Kopplin, Ph.; Hertkorn, N.; Garrison, A. W.; Freitag, D.; Kettrup, A. Anal. Chem. 70, 3798-3808.

20. Andreux. F.; Portal, J. M.; Schiavon, M.; Bertin, G. In: Study and Prediction of Pesticides Behaviour in Soils, Plants and Aquatic Systems. Mansour, M. Eds, GSF Munich, 1990, pp 100-110.

21. Offord, R. E. Nature 1996, 211, 591.

22. Compton, B. J. J. Chromatogr. 1991, 559, 357.

23. Garrison, A. W.; Schmitt, Ph.; Kettrup, A. J. Chromatogr. A 1994, 688, 317-327.

24. Schmitt, Ph.; Garrison, A. W.; Freitag, D.; Kettrup, A. Water Res. 1997, 31, 2037-2049.

25. Schmitt, Ph.; Poiger, T.; Simon, R.; Garrison, A. W.; Freitag, D.; Kettrup, A. Anal. Chem. 1997, 69, 2559-2566.

26. Schmitt-Kopplin, Ph.; Fischer, K.; Freitag, D.; Kettrup, A. J. Chromatogr. A 1998, 807, 89-100.

27. Schmitt-Kopplin, Ph.; Garrison, A. W.; Perdue, E. M.; Freitag, D.; Kettrup, A. J. Chromatogr. A, 1998, 807, 101-109. 